\title{
An Arts-Integrated Approach to Learning Mathematics through Music: A Case Study of the Song " $e$ is a Magic Number"
}

\author{
Christopher C. Tisdell ${ }^{\mathrm{a}, \mathrm{b}}$ \\ Corresponding author: Christopher Tisdell (cct@unsw.edu.au)

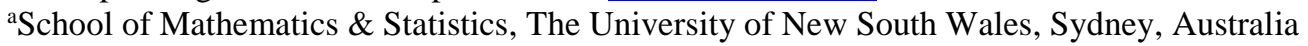 \\ b Institute for Teaching and Learning Innovation, The University of Queensland, Brisbane, Australia
}

Keywords: arts integrated teaching, mathematics, online, lyrics, music

\begin{abstract}
In this work I examine a case of arts-integrated teaching in mathematics by investigating a piece of lyrics and music. The song under investigation was designed to inspire and explain mathematical concepts of the number $e$ through verse. Through personal reflection, I discuss the inspiration, perspectives and influences in creating the song. I offer a critical examination of the design of the song, linking the design with scholarly educational principles. I illustrate how the piece was written, composed, recorded and shared online; and I identify how my process afforded minimal barriers to entry. An analysis of the online viewer metrics took a mixed-methods approach and included: comments, watch time, sharing, engagement and other metrics. My work presents new perspectives in teaching mathematics and the results support the position that there is a place for lyrics and music when learning and teaching in online, open and scaled environments. This work is of interest to researchers, educators and those who may be considering using songs for learning.
\end{abstract}

\section{Introduction}

The integration of disciplines has been shown to have powerful effects on learning (An, Capraro, \& Tillman, 2013; Drake \& Burns, 2004; Chemi \& Du, 2017). Incorporating music into educational experiences can be considered as an example of arts-integrated learning and teaching. The use of music in mathematics and science instruction has been discussed by a number of researchers, which I outline below.

Raja (2017) explored the effects of music-blended teaching on anxiety, interest and performance of students with mathematical learning disabilities in an Indian high school. Tsin (2014) examined using music within classrooms of Generation Y students at a Malaysian university's foundation year. Crowther, McFadden, Fleming and Davis (2016) assessed the impact of music videos with science-based lyrics on content knowledge and attitudes in K-12 students in New Zealand. An et al. (2013) investigated the way teachers integrate music into mathematics lessons and the effects of music-mathematics interdisciplinary lessons on elementary school students' mathematical abilities of modelling, strategy and application. Governor, Hall and Jackson (2013) interpreted the experiences of students and teachers when science-content music was used as a strategy in the middle school science classroom. Each of the above works presented positive and illuminating findings that collectively suggest there is a place for music and lyrics in the teaching and learning of mathematics and science within traditional classrooms.

Much of the research on the effects of music in the classroom has been situated within the environment of young children and school-aged learners with aims of improving memory, 
motivation, learning and creativity (Jackson \& Gilbert, 2009); however music is rarely used or researched in university-level science and mathematics courses (Crowther, 2012). In addition, considerations that explore music and teaching in online, digital and scaled environments appear to have been sheltered from discussions.

Lesser has extensively written songs and lyrics for mathematics teaching (Lesser, 2014a; $2014 b ; 2015)$. He states that songs with lyrics can be a valuable vehicle for learning and engagement; and are popular amongst students of all ages. Furthermore, Lesser identifies the potential for lyrics to act as pedagogical tools in courses from higher education by discussing how they can enhance students' learning in college-level mathematics and statistics classes.

In this work I examine a special case of arts-integrated teaching in mathematics by investigating a piece of mathematical lyrics and related music entitled: " $e$ is a magic number". Through lyrics and music, the particular song under investigation was designed to inspire and explain some aspects of the number $e$ (Moar, 1994). For this case study I offer backgrounding on: what inspired me to create the song; the educational design principles drawn upon; the technology employed to create the song; and how users interacted with the song after it was uploaded to YouTube.

Through personal reflection, I discuss what the particular inspiration, perspectives and influences were in creating the song. I critically examine the song's design, linking it with well-known educational principles in the literature. I illustrate how the piece was written, composed, recorded and shared online; identifying barriers to entry and ensuring these were minimal. Finally, I offer an analysis of what the online reception of the song was, drawing on viewer analytics such as: comments, watch time, sharing, engagement and other metrics.

As we can see from the above discussion, the intent of this paper is to explore the merit of using music in the teaching and learning of mathematics by asking questions that involve 'what' and 'how'. This strategy thus aligns with Yin's (2014) principles regarding appropriate case study research and focuses "on contemporary phenomena within contexts of the real world" (Tisdell \& Shekhawat, 2019, pp.2-3).

This case study brings three important fields together in the research domain. It lies at the intersection of: arts (lyrics, song, music, images); mathematics (the number $e$ ); and digital education (online, open streaming video; scaled education). This type of intersection appears to have remained sheltered from discussions in the research literature. I hope that this work will be of interest to researchers, educators and those who may be considering using songs and lyrics for learning - especially in online, open and scaled environments.

\section{The inspiration}

Music is a fundamental part of our evolution and forms a core human experience (Schulkin \& Raglan, 2014). Like many people, I have found music to be very special and when I look back at my own life, I acknowledge the important role it has played therein. For example, as a teenager I eagerly sought out and embraced new sounds and musical trends. If I wasn't listening to music, then I'd be thinking or talking about music, or chasing down records amassing a huge music collection as a result. After turning $18 \mathrm{I}$ went to university and regularly shared this love of music with others, performing as a DJ for 10 years across Australia, with the occasional international 'gig'. My practice of sharing music continued when I established a mail-order record service that I ran out of a spare room for five years. 
When I reflect on my transition into an academic career, it seems very natural to me to explore the roles that music could play in my practice of teaching and learning. Given my love of teaching mathematics and my musically-influenced background, bringing music and mathematics education together seemed like something I had to personally get involved with. This personal relevance aligns with the view of Acker:

Many of us study aspects of our autobiographies partially disguised as a 'detached' choice of an interesting problem (quoted in Edwards, 1993, p12).

Of course, my situation is not unique in having a strong interest in music and mathematics. Many of my mathematician colleagues enjoy music on a range of levels listening, playing, writing and even conducting. While there is no axiomatic foundation for music theory in modern mathematics, the essence of musical sound can be described mathematically (e.g. in acoustics) and exhibits "a remarkable array of number properties" (Smith Brindle, 1987 p 42-43). This includes, for example, expressing musical scales in terms of numerical ratios.

\section{Background on the number $e$}

For those who may be unfamiliar with the number $e$, allow me to provide some brief details. The number $e$ is a mathematical constant that is approximately equal to 2.7183 . It can be characterized in many different ways using calculus, including: as the limit of a particular sequence that arises in the calculation of compound interest, namely

$$
e=\lim _{n \rightarrow \infty}\left(1+\frac{1}{n}\right)^{n}
$$

or graphically as the unique positive number such that the graph of an exponential function has a slope of 1 at 0 ; or as the sum of a particular infinite series, namely

$$
e=1+\frac{1}{2 !}+\frac{1}{3 !}+\frac{1}{4 !}+\cdots
$$

For more on the mathematical basis and context of the number $e$ see, for example, Moar (1994).

The number $e$ "has traditionally had to dwell in the shadow cast by the headline-grabbing $\pi$ " (McCartin, 2006), see also Glaz (2010). According to Maor (1994) this is because $\pi$ has a history going back to ancient times and it is accessible without knowledge of advanced mathematics. Indeed, $\pi$ is one of the most celebrated numbers in all of mathematics, including within social and humanistic research contexts (Borwein \& Bailey, 2014). This includes recognition through: $\pi$ day (Lesser, 2004); popular books on $\pi$ (Posamentier \& Lehmann, 2004); poetry and songs about $\pi$ (Lesser, 2014a; 2014b; 2015; Lewellen, 1987) and so on.

On the other hand, the number $e$ is less well known. It is of a more modern vintage (Moar, 1994) and its history is connected with calculus - a less accessible subject that is not usually seen by students until the later years of high school or early university (if at all). There is no "e day"!

In light of the above imbalance, my lyrics and music embodied as " $e$ is a magic number" can be grounded in 'critical theory' (Held, 1983). The field of critical theory takes the position that 
domination is a problem (Fuchs, 2015) in society and culture. When viewed through this lens, " $e$ is a magic number" can be seen as my contribution to the struggle to form a more humanistic view of the number $e$, and more generally, to promote alternative perspectives beyond the domination of $\pi$ in hopes that we can make 'more than one pattern' as educators (Sumner, 1906) and as mathematicians.

\section{The lyrics}

\section{$e$ is a magic number}

By Dr Chris Tisdell

$e$ is a magic number.

Yes it is,

It's a magic number.

All across our scientific community,

You'll find $e$,

'Cos it's a magic number.

Difficult science was Bernoulli's pleasure.

Pleasure and learning start in the heart.

$e$ was born when Bernoulli measured,

Compound interest in small time parts.

More than 2 but less than 3,

$e$ is nearer 2.7183 .

Originally " $b$ " but changed to " $e$ ",

By Euler who wrote it as an infinite series!

Not everybody wants a $\mathrm{PhD}$,

Not everyone wants a math degree,

But number $e$ is the best,

And you must confess,

Love for Bernoulli and $e$,

'Cos it's a magic number.

$e$ is kinda related to $\pi$,

Both irrational they go on and never die,

$e$ to the i $\pi$ plus 1 equals zero,

Euler's formula and $e$ is the hero.

Showing true position,

Respect to Napier for logarithms

Although he never mentioned $e$ explicitly.

Transcendental as it may be,

It's found in probability.

Oh how I love that magic number $e$ !

$e$ is a magic number.

Yes it is,

It's a magic number. 


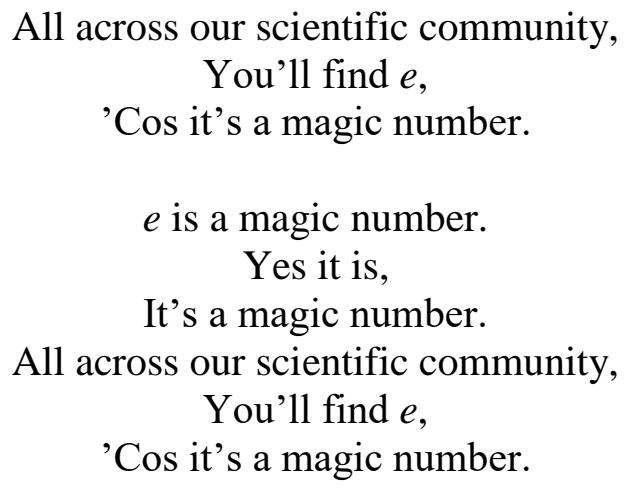

The above lyrics are not the first to appear in the literature regarding the number $e$. The piece complements, for example, Glaz's (2010) iconic poem about the same number. Glaz's poem is a significantly longer piece that goes into far more depth and detail. This may be because Glaz's work is designed to be read or spoken, rather than sung, and this may afford deeper and more complex phrases and words to feature. In addition, a search on YouTube reveals several songs regarding $e$ that use various musical styles (e.g. Wedge, 2010; May, 2015). Similar to my own piece, these works are typically short and snappy, and sung for less than 2 minutes in duration.

\section{Educational design principles of the lyrics}

Lesser (2014a) discusses how mathematics songs can have many possible uses, including: aiding encoding, storage and recall of basic facts; introducing concepts or terms; reinforcing mathematical thinking processes; connecting mathematics with history; connecting with the real world; and humanizing mathematics.

The song " $e$ is a magic number" is one of those works that aligns with all six of the above dimensions and thus forms the basis for an appropriate case study to explore and illustrate the potential of lyrics and song in mathematics education. Let me establish these connections below.

A mnemonic for the first five significant digits of $e$ is revealed through the lines: "More than 2 but less than 3, $e$ is nearer 2.7183". The 3 in the first line above is designed to form a rhyme with the final digit in the approximation through repetition. The view of mathematics as a vertical subject, where it is difficult to climb without a solid foundation, leads us to see value in learners developing a solid ability to encode, store and recall information so that they may progress to higher educational goals (Tisdell, 2019). Thus, these lines were designed with mnemonics in mind. The given approximation of 2.7183 is precise enough for most practical purposes as the error is less than $0.0007 \%$. The first line above also provides simple bounds on $e$ (that is, $2<e<3)$, clearly separating it from $\pi(3<\pi<4)$.

In addition, the lyrics introduce several mathematical terms: irrational, transcendental; and the term 'infinite series'. These specific connections with the number $e$ aim to provide some concreteness to the concepts. For example, $e$ (like $\pi$ ) is a particular example of an irrational number.

Furthermore, the line "By Euler who wrote it as an infinite series!" is designed to reinforce mathematical thinking (and) processes. How might we mathematically express numbers via alternative forms, such as series? How can we reconcile the cognitive dissonance of the infinite (sum) and the finite (number) through these sorts of processes? 
The line "Originally $b$, but changed to $e$ " connects the lyrics with the history of the symbol regarding $e$. It marks an important change when Euler's " $e$ " symbol replaced Leibniz's " $b$ " symbol - a change that is still in place today. This historical acknowledgement illustrates how convention and notation changes throughout time in mathematics with this realization forming an important aspect of teaching and learning mathematics.

Additionally, the lyrics connect to the real world through mention of a basic application. The lines " $e$ was born when Bernoulli measured, Compound interest in small time parts" illustrate the application (and indeed, the very introduction) of the number $e$ to finance and the task of computing compounding interest.

There are a number of lyrics throughout the work that attempt to show a human character of mathematics. This includes associating human characteristics with the number such as: " $e$ was born"; "love for Bernoulli and $e$ "; and "Pleasure and learning start in the heart". This opens the door for learners to think about how mathematics is a human endeavour and a dynamic field as opposed to a universally static, rigid and unchanging area.

\section{The process of writing the lyrics}

The lyrics for " $e$ is a magic number" represent part of the products of my learning and research (Shaw \& Green, 2002, p.122). However, "the processes of learning and research" (Shaw \& Green, 2002, p.122) are also significant and of interest to the research community. Allow me to unpack some of the processes associated with my journey.

The lyrics to the piece were influenced by a (now) classic song "The Magic Number" (The Magic Number, 2019): a 1990 single by hip hop trio De La Soul (De La Soul, 2019), released on their 1989 album, 3 Feet High and Rising. In the song, the trio state that the number three is the magic number. As was the style at the time, De La Soul's piece sampled a range of wellknown artists including Led Zeppelin and Johnny Cash. Most relevant for my situation is that the chorus therein is based on a segment "Three is a Magic Number" from the children's educational TV show Schoolhouse Rock!, written by Bob Dorough (Schoolhouse Rock!, 2019). De La Soul's song gained notoriety at the time of release, achieving top 10 status in the UK in 1990 and enjoying success in the US Billboard charts (The Magic Number, 2019).

Motivated by the above, my first step was to adapt the line " 3 is a magic number" in De La Soul's work to " $e$ is a magic number". I then set about telling a story by incorporating interesting elements of the number $e$ into the rest of my lyrics. The process of writing the lyrics took a weekend, using the published lyrics of "The Magic Number" as a point of reference (De La Soul - The Magic Number, 2019). This acted as a framework, helping to guide my thought processes.

To draw on Dewey (1910), each phase in my journey of writing can be considered a step from something to something. Each of my 'terms of thought' left a deposit which was utilized in the next term. The stream or flow became a connected tree, chain, or thread that manifests itself as the complete lyrical work. These series of thought stages have not necessarily been simple or linear. Indeed, Figure 1 is a photo from my original writings and it reveals a lot of crossed out lines and rewriting, suggesting that much of the creation was a process of iteration, back-andforth. 


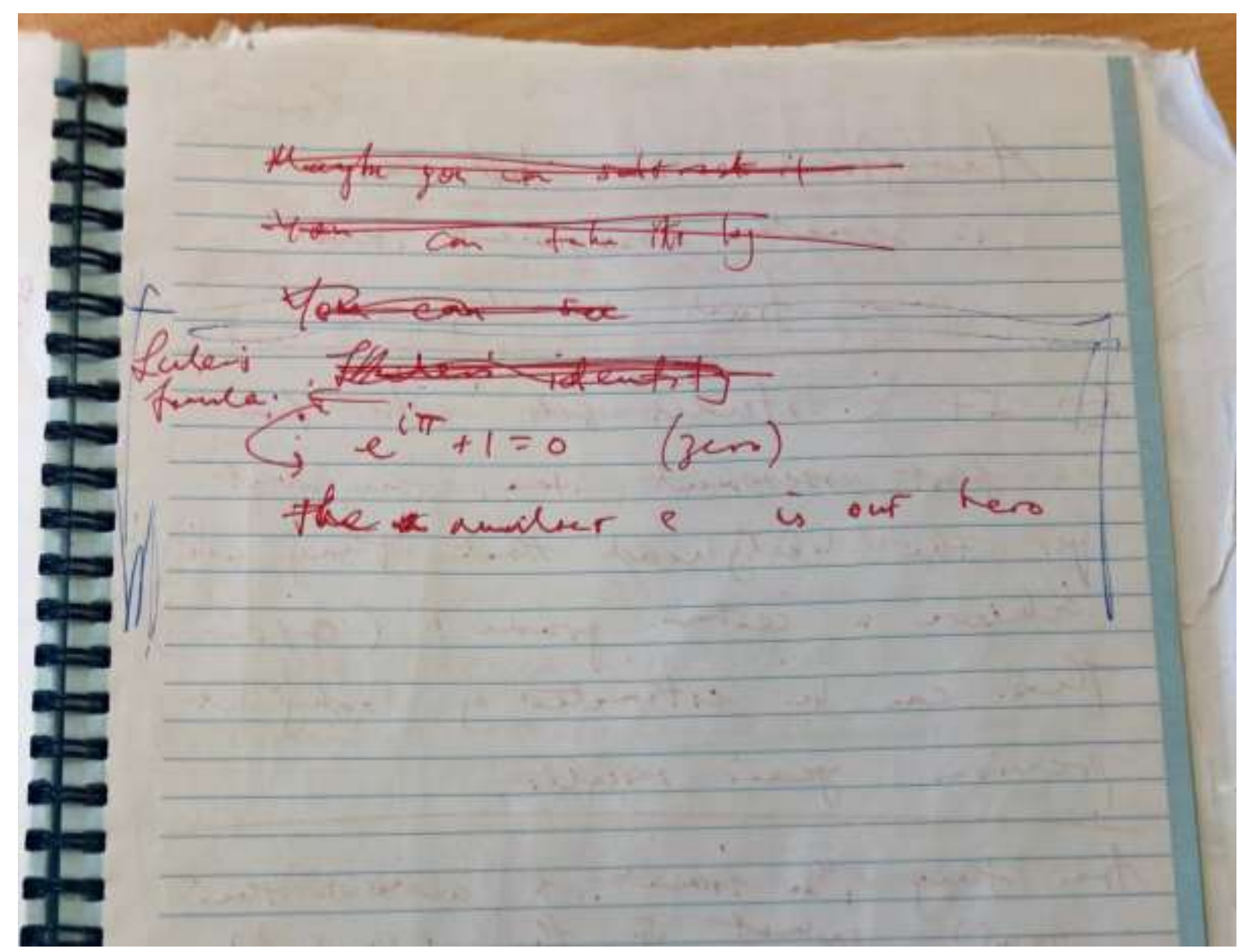

\section{Figure 1: Photo from the process of writing and rewriting the lyrics}

\section{Composing the music}

During and after the process of writing the lyrics I was faced with a second challenge. How was I to form the accompanying music for the lyrics? Not all lyrics require music, for example, poems can be spoken sans musical accompaniment. However, I decided to compose and produce some music because I believed it would add an element of multi-modality that would be appealing to learners. Furthermore, this strategy could be grounded within Gardner's concept of multiple intelligences (1983) particularly in this instance, in musical intelligence and linguistic intelligence.

I decided to write the music on my computer using the program GarageBand (GarageBand, 2019). GarageBand is a music creation studio from Apple. Its library of sounds includes instruments, presets for guitar and voice, and selections of session drummers and percussionists. Because it has a range of pre-made samples, loops and instrumentation that a creator can select, drag and drop, it can provide low barriers to learn, play, record, create and share music. GarageBand enables creators to work with or without an instrument.

I must confess here that I have had no serious musical training in my life. My particular approach was to it keep it simple and short. For example, the accompanying music involved just four main tracks: a drum loop to keep the tempo/beat; a catchy string sample acting as a hook or melody; some synthesizer sounds to provide additional melody; and a vocal. The first 
three tracks were selected from the GarageBand library after searching and testing. I decided to sing the vocals myself, recording directly into GarageBand. I confess that I have almost zero singing ability. The process of creation of the music took a few evenings worth of work. The length of the song was kept short to approximately 2 minutes, realizing that longer pieces may risk losing the attention of online listeners and learners.

On reflection, I realize that few musical skills were required in the above process, in part due to the simplicity of programs like GarageBand - an important observation regarding minimal barriers to entry in creating mathematical lyrics and music.

\section{Producing the video}

After producing the lyrics and music for " $e$ is a magic number", I decided to make a video clip to accompany the song. The benefits that I identified in doing so included adding some visual aesthetic and meant that the package could be shared on the video hub YouTube (or similar video-sharing platform), presenting the work as a scalable, open and shareable educational resource.

To form an accompanying video clip, I employed iMovie (iMovie, 2019). iMovie is a video editing software application from Apple for the Mac and iOS (iPhone, iPad, iPad Mini). Once again, I found the program relatively easy to access and use. Guided by the timing of the lyrics, I located copyright-free images from the web that formed visual relationships with $e$ and placed them throughout the video. A key principle once again for me here was that of simplicity, spending an evening putting the video together.

Davis (1985) identifies one of the challenges of lyrics and songs: "the listener, unlike the reader, gets no footnotes and must understand the lyric as it's being performed. One confusing line or inaudible word will derail the listener's attention" (p.13). To address this, I decided to include closed captioning for the lyrics within the video. The closed captions may be thought of as acting as a bridge between poetry and sung lyrics, decreasing the risk of a viewer's derailment and aiding comprehension. There are additional desirable aspects of closed captioning within educational videos which supports their insertion, such as strengthening inclusion and diversity, with closed captions appearing to be useful for a whole range of learners as described previously by Tisdell \& Loch (2017).

\section{Online sharing and reception}

YouTube (2005) is the world's most popular online video community. YouTube offers a natural environment for educational videos due to high levels of accessibility, interactivity and engagement for the learner (Tisdell, 2017). The video clip for " $e$ is a magic number" was uploaded to YouTube in February 2014 (Tisdell, 2014) and has been openly available worldwide since that time (excluding regions where YouTube is unavailable, e.g. North Korea).

YouTube Analytics offers video creators a way of measuring the performance of their YouTube videos through metrics such as: popularity, demographics, engagement and watch-time (Tisdell, 2017). Viewers can provide feedback and perspectives in several ways. Firstly, they have the opportunity to provide high-level satisfaction data through opting to 'Like' or 'Dislike' the video. Secondly, learners can provide qualitative feedback by posting a comment regarding the video in the Comments section on the video's YouTube webpage. Thirdly, viewers are able to 'Like' or 'Dislike' existing comments about the video in case they wished 
to support or oppose existing comments. Fourthly, viewers can share the video in case they believed it may be of interest or benefit to others. Finally, viewers can subscribe for further updates from the YouTube channel in case they would like to be informed when new content is uploaded. For these reasons, "uploading the video clip to YouTube was a receptive way to begin to explore wider critical debate on the piece" (Tisdell, 2019). Utilizing the YouTube platform in the above way adds the third element of digital education to this work, forming a three-way intersection with arts and mathematics.

Before I discuss the video's online reception, let me open a line of discourse on the nature of some of the viewing trends.

As can be seen from Figure 2, the video has been viewed more than 78,000 times. In comparison, a typical video on my YouTube channel is viewed between 7,900 - 18,000 times over the same period.

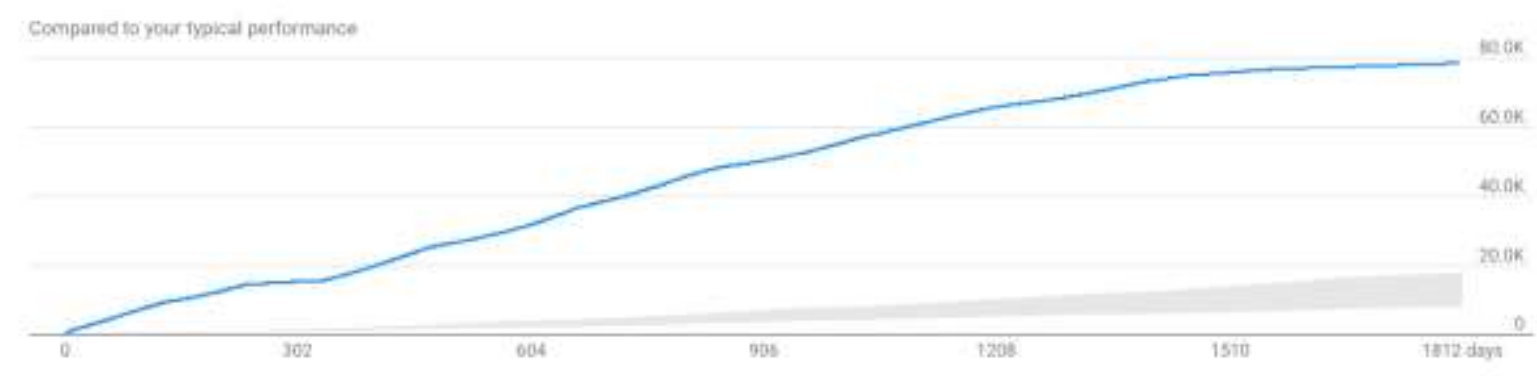

Figure 2: Cumulative number of views (blue line) against typical performance (grey zone)

As can be seen from Figure 3, the total number of minutes that the video has been watched (or total Watch Time) is in excess of 80,000 minutes. In comparison, a typical video on my YouTube channel is watched 23,200 - 54,200 minutes over the same time frame.

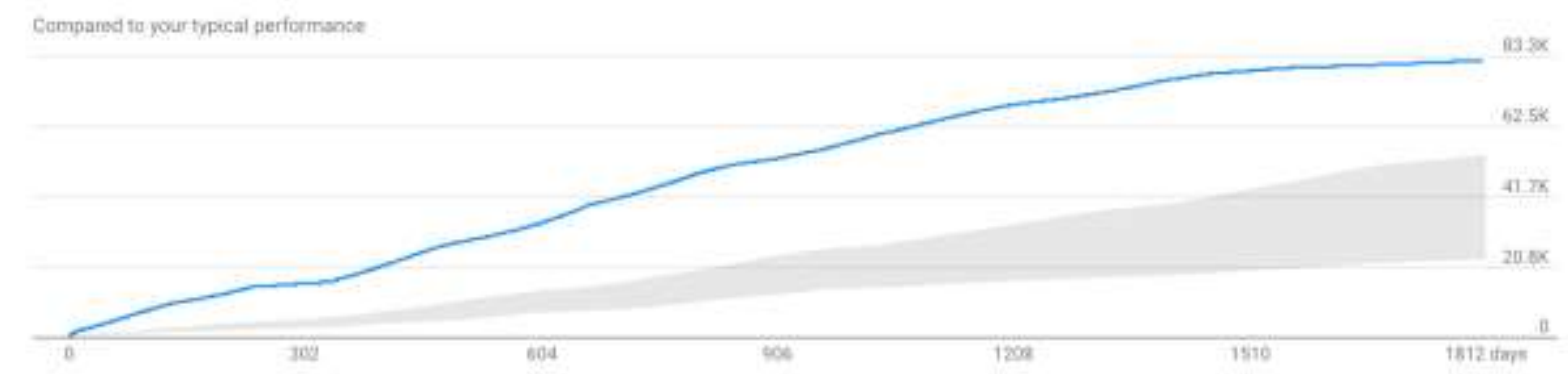

Figure 3: Cumulative watch time in mins (blue line) against typical performance (grey zone)

As we can see, the above figures and data suggest that this particular video has enjoyed more views and watch time than a typical video on my YouTube channel.

The top five geographical locations of those accessing the video with respect to Watch Time were: USA (59\%); Australia (27\%); UK (4.3\%); India (3.3\%); and Canada (1\%). As we can see from these figures, Australia is heavily over-represented regarding Watch Time perhaps due to me residing therein and mostly teaching at Australian universities. 
Viewers came to, or found, my video through four main avenues of traffic: through my own YouTube channel (45\%); through the results of a search on YouTube / Google (14\%); via suggestions appearing alongside or after other videos (13\%); and via websites and apps that embedded the video or linked to the video on YouTube $(11 \%)$.

Finally, as we can see from Figure 4, the main devices that viewers where watching the video on were: computers, such as desktops and laptops (83\%); mobile phones (12\%); and tablets $(4 \%)$.

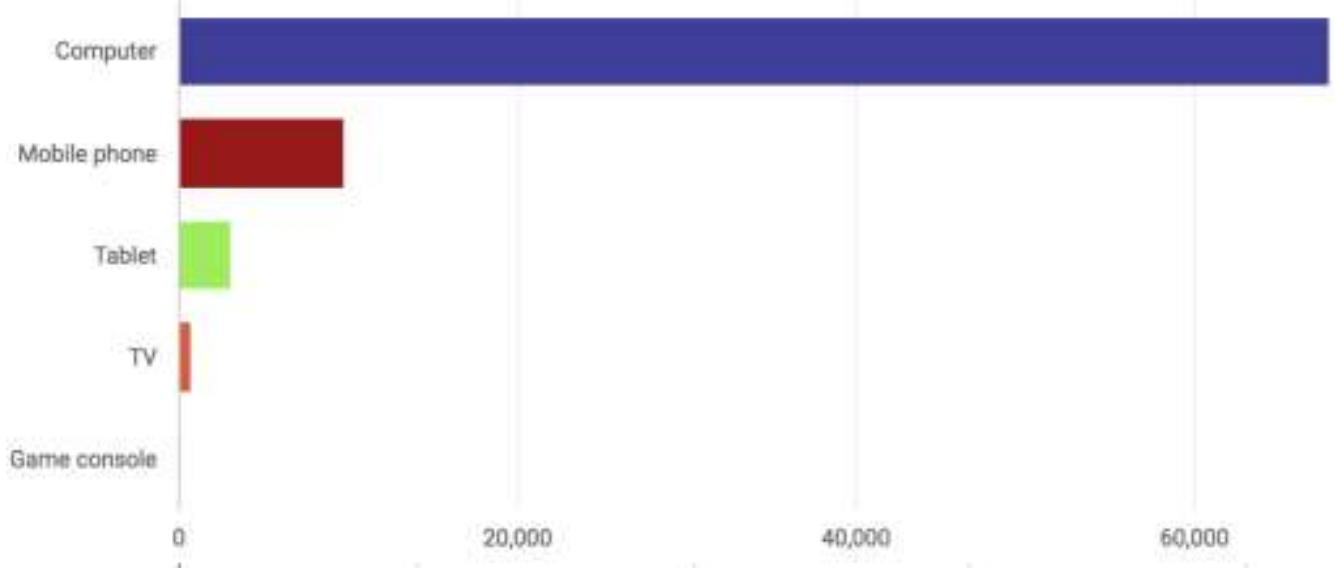

Figure 4: Levels of watch time (total minutes) across types of devices

Putting the above data together, we can form a perspective of a 'typical' viewer. They were most likely: located in the USA, who found the video through my YouTube channel, and watching on a computer.

"Research has historically indicated strong correlations between student engagement (typically defined as attention to the area of focus, active participation in learning, and time on task) and student achievement" (Dyer, 2015). Motivated by this position, let us examine the levels of audience retention associated with the video. From Figure 5 we get an overall illustration of viewer retention. We see that the average view duration of the video was 1:02, equating to $47 \%$ of the total length. At 1:02 a viewer of the video would be just coming up to the line in the lyrics regarding Euler's formula.
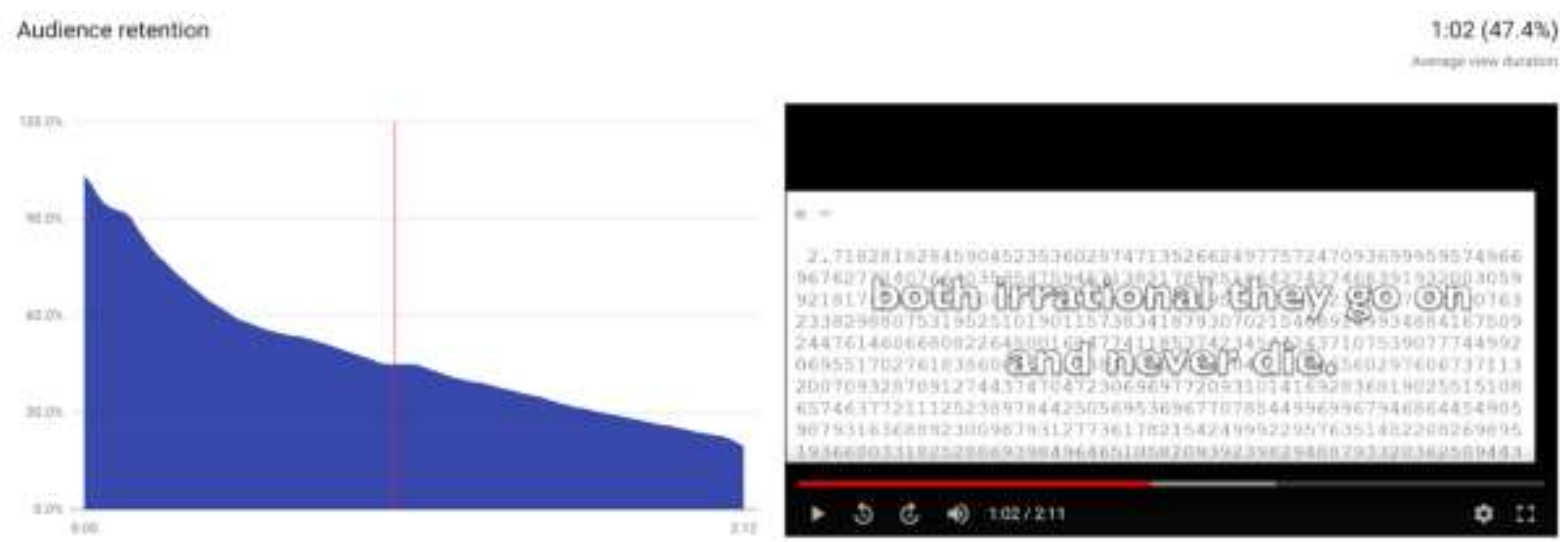


\section{Figure 5: Audience retention graph}

But how might we interpret these numbers? Let me triangulate the above data with levels of audience retention relative to all other YouTube videos of similar length. From Figure 6 we see that the relative levels of engagement for my video are classed as mostly Average with a few peaks Above Average.

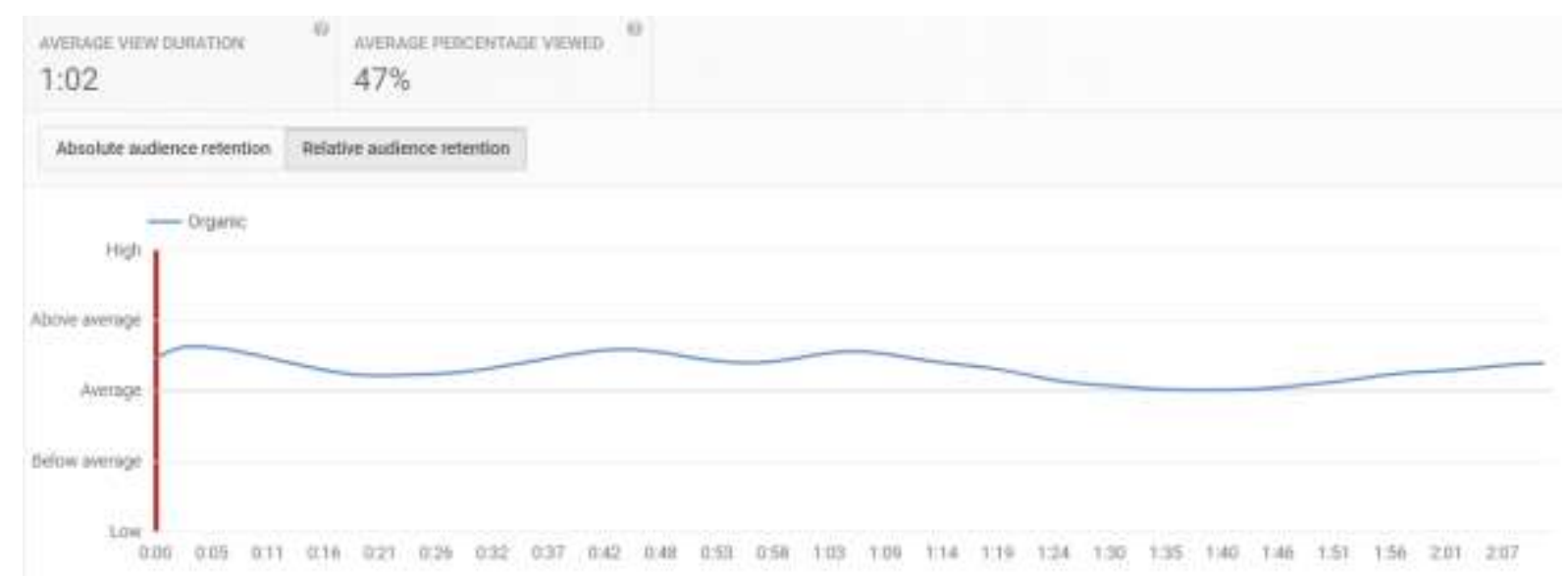

Figure 6: Relative audience retention graph

This suggests that the video's ability to retain viewers during playback was, overall, at least Average when compared to all other videos on YouTube of similar length. This realization takes on significance when viewed through the lens of student engagement suggesting there were reasonable levels of engagement being present throughout the work. Furthermore, it is probably unrealistic to expect a video about mathematics to outperform more stereotypical YouTube videos like those involving gaming, cats, toy reviews and bloopers of the same duration.

Another measure of engagement is viewer feedback. Overall, there were 399 'Likes' and 38 'Dislikes' associated with the video at the time of writing. This can be interpreted as a $91 \%$ satisfaction rate. The video has been added to 261 playlists by viewers, including to their list of 'Favourites'. The video has also been shared 319 times by viewers in a variety of ways. This includes: copying the video's URL to clipboard (34\%) so that is can be pasted and shared (for example) via email; via Facebook (19\%); and WhatsApp (14\%). As we can see from the above, there has been a high degree of satisfaction associated with the video and it has been shared repeatedly online.

There were 69 comments that were posted regarding the video. While this is a relatively small number in comparison to the total number of views, there were certain themes that can be coded from the feedback which are useful for this discussion.

Several comments identified 'fun' as a key theme:

- im doing my physics exersises listening to this. Fun...

- Fun song about not-so-fun constant :)

- hahahahahhahahahhahahhahahaa keep up .. i just subscribe u fo dis song!! h hahahha

- Somewhat amusing and quirky. 
The above theme connects with the position that fun and humour have special roles in learning and are considered an effective and appreciated tool for teaching. Studies in the literature support their importance: in the process of capturing and maintaining students' attention; in solidifying positive relationships between teachers and students; in effectively managing tension and stress; in facilitating learning and supporting retention of concepts; and in fostering creativity (Jeder, 2015).

Other comments conveyed positivity or gratitude for creating and sharing the video:

- Thanks a lot for your effort doing all of this.

- Haha this is brilliant Chris!

- Professor you are the best. I liked it

- good, it's a realy magic number

- Genious $L O L$

- great work..masterpiece..thank you for your contribution!

There were comments suggesting perceived uses or utility of the piece:

- I showed this song to my husband (physicist in the making) and now he can't stop repeating it! hahaha

- Amazing! Do you have instrumental? I want to make a cover

- I'm putting this on my ipod

- Make sure you show it to the next 3121 class students :)

Finally, comments of a more questioning or negative nature included:

- $\quad$ wheres the bleach i need to drink it

- How can you call this a "song" when you're just speaking the words?

As we can see from the above, not only were some learners expressing gratitude, but they were also exploring how they might make further use of the song, with others challenging certain aspects, identifying some limitations in the process.

\section{Discussion}

I offer some recommendations to those who may be interested in adapting the ideas herein to their own situation. The key piece of advice is to have a go! I am confident that your own perspectives on mathematics, arts and digital education will be challenged and transformed by undertaking such a process; and that your students will appreciate your efforts.

Do you need to be musically-trained to create mathematical lyrics and songs? No!! My experience suggests that an imagination for lyrics and a passion for music are both helpful, but classical training is not strictly necessary given the ease that music can be created through software such as GarageBand. People tend to get inspiration based on their own personal 
experiences and worlds, so writing "from the inside" about what is meaningful to you could be a fruitful place to begin.

For those who are new to recording music, consider experimenting with the pre-set templates on GarageBand (or similar software) first. This gets you creating music almost immediately and avoids the pressure of feeling that you need to be too creative too soon. If lyrics are sung, then try using a headset or quality microphone to ensure a higher quality of sound.

While I have mainly discussed perspectives of my own approach to the design, creation and sharing of " $e$ is a magic number" as a teacher, I am yet to explore the situation where students are tasked with putting lyrics and songs together with the aim of learning through creation. This is left for possible future research.

I acknowledge that not all songs are 'good' songs for learning; and deeper questions remain for further research that have not been completely covered herein, such as: what kinds of songs are most effective and for whom?

\section{Conclusion}

Through a personal reflection and mixed-methods approach I have explored a case study of the lyrics and song regarding " $e$ is a magic number" used in online mathematics teaching. My work complements and extends that of existing research regarding use of lyrics and music within traditional classrooms by supporting the position that music and lyrics also have a place within scaled, open and online learning environments. This article will be of interest to researchers, educators and anyone who is considering using songs and lyrics for learning and teaching, especially within digital environments.

\section{References}

An, S., Capraro, M., \& Tillman, D. (2013). Elementary teachers integrate music activities into regular mathematics lessons: Effects on students' mathematical abilities. Journal for Learning Through The Arts: A Research Journal on Arts Integration In Schools and Communities, 9(1). doi: 10.21977/d99112867

Borwein, J., \& Bailey, D. H. (2014, March 14). We still can't get enough pi . . but why? The Conversation. Retrieved February 05, 2018, from https://theconversation.com/we-still-cant-get-enough-pi-but-why-23960

Chemi, T., \& Du, X. (Eds). (2017). Arts-based methods in education around the world. Gistrup, Denmark: River Publishers

Crowther, G. (2012). Using science songs to enhance learning: An interdisciplinary approach. CBE-Life Sciences Education, 11(1), 26-30. doi: 10.1187/cbe.11-08-0068

Crowther, G., McFadden, T., Fleming, J., \& Davis, K. (2016). Leveraging the power of music to improve science education. International Journal of Science Education, 38(1),73-95. doi: 10.1080/09500693.2015.1126001

Davis, S. (1985). The Craft of Lyric Writing. Cincinnati (OH): Writer's Digest Books

De La Soul. (2019). Retrieved August 10, 2018, from https://en.wikipedia.org/wiki/De_La_Soul

De La Soul - The Magic Number. (2019). Retrieved August 10, 2018, from https://genius.com/De-la-soul-themagic-number-lyrics

Dewey, J. (1910). How we think. Lexington (MA): D.C. Heath.

Drake, S., \& Burns, R. (2004). Meeting standards through integrated curriculum. Alexandria, Va.: Association for Supervision and Curriculum Development.

Dyer, K. (2015). Research proof points - Better student engagement improves student learning. Teach. Learn. Grow. The education blog. Retrieved August 10, 2018, from https://www.nwea.org/blog/2015/researchproof-points-better-student-engagement-improves-student-learning/

Edwards, R. (1993). Mature women students: Separating or connecting family and education. Oxon (UK): Taylor and Francis 
Fuchs, C. (2015). Critical Theory. In The international encyclopedia of political communication, First Edition. Edited by Gianpietro Mazzoleni. Hoboken (NJ): John Wiley \& Sons, Inc. DOI:

10.1002/9781118541555.wbiepc001, Retrieved from http://fuchs.uti.at/wp-content/CT.pdf

GarageBand. (2019). Retrieved August 10, 2018, from https://www.apple.com/au/mac/garageband/

Gardner, H. (1983). Frames of Mind. New York: Basic Book Inc.

Glaz, S. (2010). The enigmatic number e: A history in verse and its uses in the mathematics classroom. MAA Loci: Convergence, April 2010, doi:10.4169/loci003482

Governor, D., Hall, J., \& Jackson, D. (2013). Teaching and learning science through song: Exploring the experiences of students and teachers. International Journal of Science Education, 35(18), 3117-3140, DOI: 10.1080/09500693.2012.690542

Held, D. (1983). Introduction to critical theory: Horkheimer to Habermas. London: Hutchinson

iMovie. (2019). Retrieved August 10, 2018, from http://www.apple.com/ios/imovie/

Jackson, N., \& Gilbert, I. (2009). The little book of music for the classroom. Bancyfelin: Crown House

Jeder, D. (2015). Implications of using humor in the classroom. Procedia - Social and Behavioral Sciences. 180:828-833, https://doi.org/10.1016/j.sbspro.2015.02.218

Lesser, L. (2004). Slices of pi: Rounding up ideas for celebrating pi day. Texas Math. Teacher. 51(2), 6-11

Lesser, L. (2014a). Mathematical lyrics: Noteworthy endeavours in education. Journal Of Mathematics And The Arts, 8(1-2), 46-53. doi: 10.1080/17513472.2014.950833

Lesser, L. (2014b). Pi will go on. GCTM eReflections, 4(2), 16

Lesser, L. m. (2015). “American Pi”: the story of a Song about Pi. Journal of Mathematics Education. 8(2):158168

Lewellen, H. (1987). Sing $\pi$. Math. Teacher, 80(4), 264

May, T. (2015). $e$ is a number! Available on Timmy May's YouTube channel https://www.youtube.com/watch?v=4iIINCzQ1Kk

Maor, E. (1994). e: The Story of a Number. Princeton (NJ): Princeton University Press

McCartin, B. J. (2006). $e$ : The master of all. The Mathematical Intelligencer, 28(2), 10-21. doi:10.1007/bf02987150

Posamentier, A., \& Lehmann, I. (2004). Pi: A biography of the world's most mysterious number. Amherst, NY: Prometheus

Raja, B. W. D. (2017). Upshot of music-blended teaching on anxiety, interest and performance of students with mathematics learning disability. Science Journal of Education, 5(4), 164-173. doi: 10.11648/j.sjedu.20170504.17

Schoolhouse Rock!. (2019). Retrieved August 10, 2018, from https://en.wikipedia.org/wiki/Schoolhouse_Rock!

Schulkin, J., \& Raglan, G. (2014). The evolution of music and human social capability. Frontiers in Neuroscience, 8. doi: 10.3389/fnins.2014.00292

Shaw, M., \& Green, D. (2002), Benchmarking the $\mathrm{PhD}$ - a tentative beginning, Quality Assurance in Education, 10(2), 116-124

Smith Brindle, R. (1987). The New Music. Oxford (UK): Oxford University Press

Sumner, W. G. (1906). Folkways. A study of the sociological importance of usages, manners, customs, mores and morals. Boston: S.n.

The Magic Number. (2019). Retrieved August 10, 2018, from https://en.wikipedia.org/wiki/The Magic_Number

Tisdell, C.C. (2014). $e$ is a magic number. Available on Dr Chris Tisdell's YouTube channel https://www.youtube.com/watch?v=UFgod5tmLYY

Tisdell, C.C. (2019). On mnemonic instruction and the SHIELDS acronym in the pedagogy of first-order differential equations. Teaching Mathematics and its Applications: An International Journal of the IMA, hry001, https://doi.org/10.1093/teamat/hry001

Tisdell C.C. (2017). How do Australasian students engage with instructional YouTube videos? An engineering mathematics case study. In Proceedings, AAEE2016 Conference, Australasian Association for Engineering Education (AAEE) Annual Conference, Coffs Harbour, Australia, 04 - 07 December 2016, http://www.aaee.net.au/index.php/resources/category/13-2016\#

Tisdell, C. \& Loch, B. (2017). How useful are closed captions for learning mathematics via online video? International Journal of Mathematical Education in Science and Technology, 48(2), 229-243 http://dx.doi.org/10.1080/0020739X.2016.1238518

Tisdell, C. C., \& Shekhawat, G. S. (2019). An applied e-mentoring model for academic development, reflection and growth. IJ-SoTL, 13(2):, Art. 6 https://doi.org/10.20429/ijsotl.2019.130206

Tsin, I. Y. P. (2014). Using science songs for engaging generation y students. In Proceedings of the future of education 4th Ed, 12th - 13th June 2014, Florence, Italy https://conference.pixelonline.net/FOE/files/foe/ed0004/FP/0756-ENT501-FP-FOE4.pdf 
International Journal of Innovation in Science and Mathematics Education, 27(7), 46-61, 2019

Wedge, D. (2010). 2.71828183: The Number $e$ Song. Available on Daniel Wedge's YouTube channel https://youtu.be/ZPGHuuk2bKw

Yin, R. (2014). Case study research. Los Angeles: Sage

YouTube. (2005). Retrieved August 10, 2018, from http://www.youtube.com 